\title{
Analysis of the Statement as a Tool in the Study of the Functional Standards of Style
}

\author{
Vladimir Anatolyevich Burtsev ${ }^{1}$
}

\author{
${ }^{1}$ Department of Linguistics and Documents Study, Institute of Philology, Yelets State Bunin University \\ 399770, Yelets, Lipetsk, 28 Kommunarov Str., Russian Federation \\ Correspondence: Vladimir Anatolyevich Burtsev, Department of Linguistics and Documents Study \\ Institute of Philology, Yelets State Bunin University. E-mail: ivburcev@yandex.ru
}

Doi:10.5901/mjss.2015.v6n5s4p340

\section{Abstract}

The article describes the style properties of complex sentences of conditions and causes. These syntactic forms are recognized as style-creating for all book written styles of modern Russian literary language. This paper, however, proves that they also constitute a special stylistic layer of church and religious identity. Style properties of conditional and causal sentences are set not by stylistic, but discursive way-building on the analysis of the act of utterance and denotative situations that underlie the use of sentences in religious and non-religious texts. Distinctive features were described in the statement of the act of saying this sentence in accordance with the act of statements of another sentence of the same type of syntax in different denotative situations. This approach to the stylistic characteristics of linguistic phenomena claim to their full semantic definitions as the basis of the symptoms denotative situation, it is always to answer the question of what information expressed by the statement: conventional or subjectivized information. It is enough for the type of sermon texts in which we have to deal not only with the style, but also with the discourse. The discourse of preaching demonstrates causal and conditional complex sentences becoming distinctive due to specific denotative situation functional and stylistic values, which play an essential role in the creation of syntactic tier of church and religious identity. This study shows that the statements, built on the basis of conditional and causal sentences in religious and scientific language, have a different nature: designatum of the first is a fact, and designatum of the second is an event. Typical identity of these sentences has no place in situations of their use in the scientific and religious styles. In general, the studied syntactic means are highly and stylistically, and discursive significance for Orthodox sermon.

Keywords: style language, church-religious style, discourse, preaching, sentence, statement, proposition, propositional content, presupposition, transformation

\section{Introduction}

The problem of stylistic differentiation of the literary language is revealing the limits of its functional versions are always acute for linguistic style. Its production is primarily concerned with the fact that "no kind of language does not have by any means that could be used in another" (Shchmelev, 1977). Constant interaction of different nature of language means in different spheres of human activity makes difficult to define the boundaries of language styles. Today, this problem is less relevant than half a century ago, when only worked out the principles of classification of functional styles (Vinogradov, 1955). To a large extent, it is dictated by the need to describe the new stylistic system of modern Russian stylistic variety—church-religious style (hereinafter-CRS) (Krysin, 1994, 1996; Krylova, 2003). This paper presents a case study of its stylistic features within the leading CRS genre-preaching (sermon). This is done through a semantic-syntactic plan of speech, without the involvement of which is represented as CRS syntax is viewed as non-style-forming tier.

\section{Literature Review}

Over the past twenty years, Russian Studies has experienced a great work on the study of language when it is used in the religious sphere of communication. It was made from different perspectives: stylistic (Bugaeva, 2003; Voytak, 2003, Krylova, 2003; Krysin 1994; 1996; Prokhvatilova, 1999), communicative (Bugaeva, 2008; Krylova \& Savin, 2008; Rozanova, 2003), discourse (ive) (Bobyreva, 2007; Karasik, 1999), cognitive (Bulygina \& Shmelev, 1997; ListrovaPravda, 2001; Panova, 2000), semiotic (Mechkovskaya, 1998), and rhetorical (Coussay, 2003).

The special approach to the analysis of the religious use of language-theolinguistics-is formed in foreign linguistics. According to A. Gadomskiy (Gadomskiy, 2005), the subject of theolinguistics includes a description of (1) as a human word can be as used in relation to God, (2) how language functions in the religious situation, (3) what is the 
language of biblical scholars, theologians and other persons involved in the theory of religion.

There are also many other works on religious language, which are dedicated to specific issues (Averyanova, 2014; Zhulynskaya, 2005; Zavalnikov, 2003; Ivanova et al., 1998).

On the other hand, some of the study areas of the language of religion practically do not yet represented in the study, for example, the language of Orthodox preaching in its relation to different periods of the history of the Russian literary language.

As for the Russian Orthodox sermons, then most of these approaches were applied to its material. We considered stylistic means, ways of expressing mental categories and concepts, types of speech genres and forms of expression, rhetorical means and techniques of persuasion presented prosodic characteristics of different types of sentences, determined features compositional structure of texts. This material is important in itself. Moreover, it is differential enough for typological analysis. This typological aspect is crucial to explain the features of the individual style of language or discourse (Kibrik, 2009). In varying degrees, the typological perspective is the subject of many studies, including those carried out on the material of preaching, including the Orthodox sermon (Bobyreva, 2007; Krylova, 2005; Takhtarova, 2010; Shchukina, 2010).

However, much of the research with the typological aspect significantly downplayed differences between CRS and other styles. Quite often it noted that some language levels, essential for CRS, and other styles, do not exist at all. In our opinion, this is due primarily to the fact that typically there are no distinguishing between the language and the product (using) the system in case of speech. From this point of view, for example, the syntax of CRS demonstrates just what characterizes the use of quotations, which they tend as a unit of the grammatical system of popular language, and nothing beyond that.

This paper shows that the difference between the supply system as a unit of language and utterance as a unit of speech is a fundamental principle of linguistic study of functional-stylistic norms of use of system resources in a variety of speech, as CRS.

\section{The Methodology of the Study}

Clearly, CRS, as well as any other style, features the language, the most functionally oriented is a vocabulary that as vocabulary CRS pretty easy to unambiguous interpretation (saint, reverend, apostle, heathen, to baptize, baptism, Christian, martyr, proselyte, sinner, confession, church, sacrament, anointing, repentance, the Kingdom of Heaven, prayer, spiritual father, Calvary, Easter, angel, Gospel). Another thing is the CRS syntax. This area has the least of all stylistic means associated with the phenomenon of stylistic colouring. Among them, style-forming are major syntactic types of sentences that provide book nature of CRS. However, book stylistic colouring of syntactic units (like book colouring of language units of other levels) is not a stylistic feature of any one style-it characterizes all kinds of literary language, implemented a written speech. Analysis of proper syntactic forms, without an analysis of their functional role naturally leads to the conclusion that there are no specific differences in syntax between CRS and the rest book style.

The same results are obtained by the analysis of the functioning of the sentences in the framework of the concept of typical use (Lyons, 2003). For example, conditional sentences, by definition, are classes of sentences intended to express the meaning of the logical conditioning. If they are described as sentences that are typically used to express this value, and in particular the text of copies must be delivered to the function, typical for this class of sentences. We propose to consider the problem of style properties of sentences in terms of an act of expression and denotative situation. Statement means a speech segment produced by the speaker, the base of the segment is the sentence (Lyons, 1978). The act of saying is the process of production, consisting in the approval of propositions. Denotative situation is a situation (described by the propositional content of the sentence).

We believe that there are denotations and denotative situations which by their objective properties allow only a single interpretation of the utterance. For example, sentence

Temple is the heaven on earth may be a religious statement, only if denotata's timeless identity is presupposed. (1)

The ability to present from the speaker in his statement a situation in which it would be reflected episodic denotata identity (such as Temple was (will be) the heaven on earth), is unacceptable for religious statements.

Since the description of situations unambiguous semantic representation of the speakers is actually related to the conventions and not with locutive activities will qualify this value as conventional. Conventional value is not approved, as is implicit. Therefore, necessary conditions for ensuring the stylistic value of the sentence are its presuppositions as a religious statement. In our view, presuppositions are those components of the sentence meaning that are not subject to 
denial and to be true to the sentence was not perceived as inappropriate, or false (Paducheva, 1990; Kiefer, 1978).

As it will be shown below, sermon motifs to form the semantics of statements based on conditional sentences and causal presuppositions are determined only as the recipient of the religious statements has no chance to get out of the semantic analysis of the statements of more than one interpretation. This conclusion may be, in principle, extended to any religious statements. For example, auspicial sentences (with predicates necessary) may be used with two modal values: deontic and epistemic. Deontic must has the following meaning: $X$ must do $P=$ "there exist $X$ will's independent circumstances $Q$, which force $X$ to do $P$, because if $X$ does not do $P$, then some force $F$, which is part of the circumstances of Q, cause evil to X" (Kobozeva, 2004). Epistemic must has the following meaning: $X$ must do $P=$ "among my knowledge of the world there is knowledge $Q$, which forces me to believe that $P(X)$ is (was, will be) in the world" (Kobozeva, 2004).

It is believed that the predicates need to preach always used to deontic modality, regardless of the specific form of the infinitive (perfective/non-perfective) and the reference context (transparent/opaque: (Quine, 1982)). Deontic value is determined by a causal proposition that expresses infinitive turnover in terms of their positioning model (Lomtev, 1958) in a sentence. Positional model infinitive turnover predicate the need for the sentence is the position of the sentence. Thus, the infinitive group in the sentence

It is necessary to bear these responsibilities honestly, love, without complaining, as far as the forces and capabilities (Menetrov, 1905) (2)

is correlated with the group "to + verb in past tense":

It is necessary for us to carry those duties honestly, love, without complaining, as far as the strength and capabilities. (2a)

The proper use of the verb in this context due to the proposition We do not assume these responsibilities. In turn, this proposition is a necessary condition for the admissibility of the original statements of the religious text. Neither the subject nor the recipient of an act of saying has no other way to build and interpret the statements of this type.

These features relatedness denotative utterances are put in this paper as the basis of differentiation of the considered use of language units. It is expected that this approach applies for a complete definition of linguistic facts, since we can always answer the question of what information expresses saying: conventional or subjectivized information. It is enough for the type of sermon texts in which we have to deal not only with the style, but also with the discourse. The term of discourse is used in this work to designate special sublanguage, a special subsystem within popular language (Stepanov, 1995; Pereverzev, 1998). Discourses are identified with the text, i.e. represented in the texts, which in turn are described in terms of a set of statements that are used to express a special speaking mentality and special ideology.

In this paper, we consider the scientific statements that are based on complex sentences logic of conditionality, namely on the basis of causal and conditional sentences, and compare them with semantically statements, which are made on the same basis of grammar in the language of the sermon. Our material is the same material that has been used by other researchers to justify the conclusion that the use of conditional sentences and causative in preaching is not different from their use in texts of scientific style. The general conclusion, to which we come, is to ensure that the conditional and causal sentences-this is not an instance of the same type of statements, and various statements, the process of generation of which is governed by different conditions of production in the scientific and religious texts. It is expected that the evaluation of the communicative properties of sentences of the language in the discourse allows for a more accurate assessment of their actual status as a stylistic means of language syntax.

\subsection{Conditional Sentences as Statements}

Conditional sentences are specific syntactic language means for sermons and scientific texts. This conclusion was made, in particular in the paper by (Shchukina, 2010) based on quantitative data. In this article, the question was raised about the reflection characteristics of sermons in the language of the Russian national character. Cognitive nature of speech was determined by quantitative comparison of the types of sentences used in sermons and in the scientific speech. The quantitative data presented in the study characterize our material in the same manner.

However, we believe that the cognitive nature of the question does not reveal its connection with the number of identified types of language units (Labov, 1975; Vinogradov, 1980). It seems that the purpose of distinguishing the sentences generated in the formulation of the sentence act statements in accordance with the act of saying another 
sentence.

Let us consider the following conditional sentences:
If a person falls into some grievous sin and a clear conscience if it does not completely burned and dead, it will be obvious to denounce this grievous sin (Nikolay \& Metropolite, 1950).
If there is a sphere experiences associated with $A$, then all of the realities of the sphere, of course, belong to the same category as the $A$ (Lakoff).

Sentence (3) comes the text of the sermon, sentence (4) comes from a scientific article. Let us assume that the motives of the specificity of conditional sentences in the texts of sermons are quantitative and semantic (belonging to the range of logically resulting structures) criteria. The content of communication using logical sentences arising is rational (not emotional) impact on the recipient (Shchukina, 2010). According to these parameters, conditional sentences are as specific and scientific in style. Therefore, quantitative, semantic, stylistic and communicative featured sentences (3) and (4) not demarcated. It requires further information on the nature of the statements of the sentences in the scientific and religious texts (in particular, on the properties of denotative situation and the mechanism of generation of the statement).

It may be noted that all conditional sentences are divided into two groups of such semantic features of conditional sentences as the value of "rationale". This value is set for it as a syntactic unit of scientific language. Scientific language requires conditional sentences "in the evidence, the arguments, wherever there is a statement of the assumption, followed by evidence" (Kozhina, 1972). If a conditional sentence is a rationale, in the co-text, it cannot be combined with the investigation of the word (hence, therefore, because). For scientific writing, this feature is relevant, while for the religious style it is an exception. Thus, (4) does not allow for consecutive co-text (below we present this sentence to the text under the number (4a).

It seems that the most general principle that Dixon takes it for granted and does not even find it necessary to formulate explicit-is the principle which I would call the "principle of the sphere of experience". The principle of the scope of the experience: *[Therefore] If there is a sphere experiences associated with $A$, then all of the realities of the sphere, of course, belong to the same category as that of $A$. (4a)

However, sentence (3) has the consecutive co-text (shown under the number (3a)):

Our enemy in sincere repentance is our self-deception, we do not want to ignore those sins, thoughts, movements sinful, so crowded that our heart. [Therefore] If a person falls into some grievous sin and a clear conscience if it is not quite burnt and dead, it will be obvious to denounce this grave sin.

Therefore, the sentence (3) is in line with investigative structures and their content is related to the pre-information (Weinrich, 1978). Sentence (4) is in line with implicative structures, for which the pre-information as a motive of formation of consecutive and conventional connection of predicative units does not exist. Under these conditions, parsed sentences (3) and (4) are syntactic homonyms and different statements.

Although the attitude to the sentence to the pre-text (pre-information) is a fairly effective differentiating approach, however, it is not able to distinguish all cases. Counterexample to (4) is presented in (5). Such statements in the texts of scientific style are quite regular.

The semantic domain of the predicate of rank ... embraces the values of localization in time and space, the character of the action, its implementation, and the different types of subjective-modal evaluation... [Therefore] If the secondary predicates attributed to a particular name, this is the last substantive losing references and decryption meaning of the sentence requires the deployment in the proposition (Arutyunova). (5)

For the full decision on certain stylistic values, it is possible to adopt a more formal approach to differentiate statements. It involves an attempt to find a formal relationship between the predicative propositions units and those ontological objects whose symbols they serve, namely the facts and events. That is, if the proposition refers to the fact propositional content conditions are the presuppositions; if the proposition represents an event propositional content conditions are not only the presuppositions, but locutive activity of the subject of the question. This paper proposes transformation as a formal approach. Their goal is the formation mechanism of explication statements, i.e. explication of the causal reason of conditionally investigative value.

Transformations (6a) and (6b) of the sentence (6) of preaching show how it can be subject to changes as saying, if the task is to find out what the reason was the motive conditional investigative conclusions. 
But the sectarian is a sectarian: he sees truncated, he sees just before him. And if they really wanted to know the truth, that, first, they would see that there is the same as the states of the fathers and the teachers... (Reznikov, 1995). (6)

They do not really want to know the truth. (6a)

They do not see that the same is said here (6b)

These transformations are extremely presuppositions which are constructed as a negation of sentences (for the main part, and for the subordinate).

With regard to conditional sentences of scientific style, their transformation into sentences with denial is unacceptable:

If we identify the differential element of sonority, it is assumed that in general there is a set of phonemes is its subset which has the property of sonority. (7)

${ }^{*}$ We (do not) distinguish the differential element of sonority. (7a)

*In general set of phonemes, there is (no) such a subset that has the property of sonority.

Negation affects the propositional content of an utterance (Lyons, 2003: 187), so the ability to transform negative predicative units we consider factual manifestation of the nature of its propositions, which persists despite the syntactic position expressing its predicative units (conditional sentence) and non-stated character of the propositions in the surface structure of the sentence. The unacceptability of negative transformation is the evidence of the non-factual, eventual (subjectivized) value of the proposition.

\subsection{Causal Sentences as Statements}

Causal sentences as conditional (in particular, their frequency in sermons and in the use of the functions typical of this class of sentences) are considered in the literature as a basis for identifying the language of preaching and scientific language. The following are the arguments in favour of the idea that the causal complex sentences in religious texts (sermons) and in the scientific text are statements that are not compatible by the nature of the content and method of expression.

The way to interpret causal sentences is known and its idea is to respond to different parts of the subordinate relationship to the main (Davison, 1986). The subordinate part can express: 1) the cause of the situation that is presented in the statement, or 2) "external" cause, by virtue of which the speaker said the statement.

The way of representing the subordinate relationship to the main part of the extension is to pre-position the subordinate part and the inclusion semantic representation figure of speech act or descriptive describe as a liaison between the main and the subordinate units.

Let us consider the statement of scientific style.

Extreme spraying is only a consequence of the desire of living matter to being everywhere, for the reproduction of living matter, increasing its weight in proportion to its surface (Kozhina, 1972). (7)

Since ("?because) the reproduction of living matter, increasing its weight in proportion to its surface [I say to you (I told you)], that the extreme spraying is only a consequence of the desire of living matter to being everywhere. (7a)

[I say to you] that since the reproduction of living matter, increasing its weight in proportion to its surface. (7b)

[I told you] that since the reproduction of living matter, increasing its weight in proportion to its surface. (7c)

If we accept an interpretation from the standpoint of (7b) or (7c), the clause should be considered as justification for the speech act, and not the content of the proposition Extreme spraying it is only a consequence of the desire of living matter to being everywhere. With this interpretation of the meaning, the content of the said proposition does not have a causal basis and should be qualified as a fact, as the knowledge, known to the speaker without its cause. This means that the main proposition in the generation of the original statements must precede stage of causal justification and should be regarded as "old information". That is not the case, illustrates the transformation, in which the main part of the subordinate and coordinative placed in a context that requires a sequence of statements characterized by some due to be joined in a reasonable manner (Dijk, 1978). For the following conversion (7d), there are no joinability reasonable terms, therefore, the content of statements can only be considered in terms of the relationship at the time of the act of speech, which is determined by the sequence of propositions conditioning.

* Extremely spray is only a consequence of the desire of living matter to being everywhere. The reproduction of the 
living matter, increasing its weight in proportion to its surface. (7d)

Let us check the terminals on the material, language-specific linguistics.

It does not make these positions near-substantive as the positions of the predicate and subject are allocated on the basis of respect to the position verbally to the subject and the predicate (Lomtev). (8)

* This does not make these positions near-substantive. The positions of the predicate and subject are allocated based on respect to the position verbally to the subject and predicate. (8a)

However, the syntax of these phrases is different phenomena, as syntactic units are not the form of words, and their position in the sentence (Lomtev). (9)

${ }^{*}$ But syntactically these phrases are different phenomena. Syntactic units are not the form of words, but their position in the sentence. (9a)

We believe that in the statements of (8a) and (9a), joinability reasonable condition is not satisfied. Consequently, in the reasons for the proposed (8) and (9) of a subordinate sentence justifies the main part of the content, and speech act the speaker is a statement that is subjectivized statement. Let us consider the sentence of the sermon.

The world does not condemn our deed because we have a great responsibility for it than those who do iniquity (Metropolite, 2009). (10)

Since (because) we have a greater responsibility for the world, than those who do iniquity [I inform you (I told you)], that it is not our business to condemn the world. (10a)

[l inform you], because we have a greater responsibility for the world, than those who do iniquity. (10b)

[I told you] because we have a greater responsibility for the world, than those who do iniquity. (10c)

It is not our business to condemn the world. We have a greater responsibility for the world, than those who do iniquity. (10d)

The subordinate part expresses the cause, by which the speaker has every reason to announce that "it is not our business to condemn the world". In this case, the subordinate part is presented as a fact, already taken place in the past to speak someone else. Anaphora (our-We) has an important for the admissibility meaning of the statement (10g). Anaphora is used to determine possibility/impossibility of performance terms of a reasonable possibility of joining. Anaphora is an indicator of the existential nature of the main part. Sermons contain virtually no causal sentences where the subordinate part is free of anaphoric instructions.
He is our Comforter, because in Him-Orthodox Christian source of comfort in all of its trials of life (Nikolay \& Metropolite, 1950). (11)
This is how we should confess, ...but we do not do that, because we are afraid of the ruthless, simple directness before God and before men (Metropolite, 2009). (12)
At the same time we want a new life from the Lord.... and this life is given to us, because when the Lord comes to us ... the eternal life conquers us... (Metropolite, 2009). (13)
Since it is time to repent, in these days it is good to think about where you start this repentance ... (Shumov, 1903). (14)

\section{Results and Discussion}

Thus, the propositional content of conditional sentences in a sermon is determined by one mechanism of production of statements: the relationship between the predicative units set as the ratio between the facts (between propositions to factual value). Propositional content conditional sentences in scientific texts is determined by a different mechanism of the act of saying: the relationship between the predicative units is set as the ratio between the events. Statements, built on the basis of conditional sentences in religious and scientific language, have a different nature: designatum of the first is a fact, and designatum of the second is an event. Use of the sentences in these fields is different. The thesis that the conditional sentences in the preaching and scientific speech have standard identity is not confirmed by the analysis of the statements, built on a database of grammatical sentences.

Causal sentences as conditional, are the basis for identifying the language of preaching and scientific language. We used the way the causal interpretation of sentences which is to take into account the different relationships with the main part of the subordinate. The subordinate part can express: 1) The cause of the situation that is presented in the statement, or 2) "external" cause, by virtue of which the speaker said the statement. Scientific statements are interpreted according to the first type of relations between the predicative units, religious statements-the second type, i.e. reasons for the proposed statements are presented in sermons, in which information of the subordinate part in the time of its 
adoption, is assimilated, known.

By defining sentences and statements, i.e., units of language and their use, we get objective possibilities of detection specificity stylistic use of language means. Using discourse analysis method statements, a stylistic research may qualify for a more accurate reflection of the abilities of the speakers used in the speech means the national language. Practical development of discourse analysis method semantics statements can be considered a promising area of modern linguistics.

\section{Conclusion}

The considered material, in addition to the typological and stylistic generalizations that give an idea of the CRS in the genre of the sermon as a specific phenomenon in comparison with other styles, provides another conclusion. It is important to address the acute problem of the essence of the discussion, or the nature of the sermon. It is a question of whether the preaching oratorical genre, which like all the oratorical works suggests that the effectiveness of verbal persuasion depends on the skill, dexterity speaking, or is it a sermon, despite the implementation of the strategy of persuasion destination opposed to all secular rhetorical works.

There is reason to believe that the applicability of rhetoric to preach only limited by elocutive component of rhetoric, which allows the author to give her speech to the product form adequate concepts discussed. The principle of persuasion through preaching by means of own rhetoric obviously cannot be solved. As shown in connection with the notion of presupposition, the subject of religious statements cannot express anything that would give the recipient the preconditions for a pragmatic interpretation of the statement, i.e. It would make it possible in the perception and evaluation of reality based on their background knowledge of the world, including the knowledge of the identity of the preacher, his ecclesiastical dignity, authority in the church, languages, etc. Any knowledge of the world allows ambiguous conclusions, as there is always a so-called extralinguistic ambiguity, which sometimes leads to opposite estimations of the same events. A similar situation to the sermon texts is excluded. Addressee of a sermon brings a pragmatic investigation of the statements only on the basis of presuppositions statements. It is not possible to reject accepting of presuppositions cannot be ensured and this belief; elocution plays no role in the implementation of the principle of belief in orthodox preaching. From here one can make another logical conclusion: the content of rhetorical persuasion principle in preaching is a statement. However, the aspect of statement is not to be understood literally, as a psychological activity of the speaker, and as the impact on the interpretation of the remarks field presuppositions, assistants to be associated with a religious view of the world.

\section{Acknowledgements}

The work has been prepared as part of the base part of the public task of the Ministry of Education and Science of the Russian Federation (No. 2418 "Reference of statements in terms of the perception of information and the building of the statements in the discourse of the Russian Orthodox preaching")

\section{References}

Averyanova, E. V. (2014). Semiolinguistic aspects of the Orthodox and Catholic hagiographic discourse XI-XVII centuries (based on Old Church Slavonic and Latin languages). Tyumen. Author's abstract of ... Cand. of Philol. Sciences.

Bobyreva, E. V. (2007). Religious discourse: Values, genres, strategy (based on the Orthodox Faith). Volgograd. Author's abstract of ... Cand. of Philol. Sciences.

Bugaeva, I. V. (2003). On religious preaching style in Russian (pp. 390-394). Moscow: Annual Theological Conference of PSTBI.

Bugaeva, I. V. (2008). The religious communication. Orthodox news agency "Russian line". Retrieved from http://rusk.ru/st.php?idar= 26311

Bulygina, T. V., \& Shmelev, A. D. (1997). Reference and meaning of expressions meat fare (Meat Fare Week) and cheese fare (Cheese Fare week, pp. 40-47). Questions of Linguistics.

Davison, A. (1986). Linguistic or pragmatic description: Contemplation about the "Paradox of performativeness" (pp. 235-269). Moscow: The theory of speech acts.

Gadomskiy, A. K. (2005). Theolinguistics: Background (pp. 16-26). Simferopol. Scientific record. TNU.-Vol. 18 (57).-No. 1. Philology.

Ivanova, M. V. (1998). Old Russian Lives of the late XIV-XV centuries. As a source of the history of the Russian literary language (pp. 79-87). Questions of Linguistics.

Karasik, V. I. (1999). Linguistic personality: Problems of cultural linguistics and functional semantics: Collection of scientific works. Religious Discourse (pp. 5-19). Volgograd.

Kibrik, A. E. (2009). Modus, genre and other parameters of the classification of discourses (pp. 3-21). Questions of Linguistics. 
Kiefer, F. (1978). On presuppositions (pp. 337-370). Moscow.

Kobozeva, I. M. (2004). Linguistic semantics. Moscow.

Kozhina, M. N. (1972). On speech systemic scientific style compared with some others. Perm.

Krylova, O. A. (2003). Stylistic Encyclopaedic Dictionary of the Russian language. Church and religious style (pp. 612-616). Moscow.

Krylova, O. A. (2005). Philosophical and linguo-cutural problems of tolerance: Collective monograph Tolerance, speech genres and functional styles of modern Russian literary language (pp. 194-203). Moscow. Retrieved from http://www.ino-center.ru/docl ProblemiTolerantnosti.pdf

Krylova, O. A., \& Savin, G. A. (2008). Communication Strategy of the author in Orthodox preaching in the modern Church Slavonic discourse (p. 53-59).

Krysin, L. P. (1994). On a lacuna in the system of functional styles of modern Russian language (pp. 69-71). Russian language at school.

Krysin, L. P. (1996). Language and Culture: In the memory of T. G. Vinokur. Religious preaching style and his place in the functional and stylistic paradigm of the modern Russian literary language (pp. 135-138). Moscow.

Coussay, H. (2003). Truth and preaching. "Living Word" Archbishop Ambrose (Klyuchareva, 1820-1901) and the relationship between rhetoric and homiletics (pp. 636-644). Moscow.

Labov, W. (1975). The study of language in its social context (pp. 96-181). Moscow.

Listrova-Pravda, Y. T. (2001). Methodological problems of cognitive linguistics: Scientific publication. The concept of GOD in the linguistic consciousness of the Russian people (pp. 93-102). Voronezh.

Lomtev, T. P. (1958). Basic syntax of the Russian language. Moscow.

Lyons, J. (1978). Introduction to theoretical linguistics. Moscow.

Lyons, J. (2003). Linguistic semantics: Introduction. Moscow.

Mechkovskaya, N. B. (1998). Language and religion: Lectures on philosophy and the history of religions. Moscow.

Paducheva, E. V. (1990). Linguistic Encyclopaedic Dictionary. Presuppositions (p. 396). Moscow.

Panova, L. G. (2000). Logical analysis of language: Languages of ethics. Sin is a religious concept (for example, the Russian word for "sin" and the Italian word "peccato" (pp. 167-177). Moscow.

Pereverzev, K. A. (1998). Questions of Linguistics. Saying and situation: On the ontological aspect of the philosophy of language (pp. 24-52).

Prokhvatilova, O. A. (1999). Orthodox preaching and prayer as a phenomenon of modern-sounding speech. Volgograd.

Quine, W. O. (1982). Reference and modality (pp. 87-108). Moscow.

Rogozhnikova, T. P. (2009). New in Slavic philology: Collection of articles. Reactivation of the Church Slavonic language at the turn of $X X-X X I$ centuries (pp. 93-103). Sevastopol.

Rozanova, N. N. (2003). Modern Russian language: Social and functional differentiation. Scope of religious communication: Temple mount (pp. 341-363). Moscow.

Shchukina, I. N. (2010). To the question about the reflection characteristics of sermons in the language of Russian national character (pp. 59-62). Bulletin of the University of Perm. Russian and foreign philology, 4(10). Retrieved from http://rfp.psu.ru/archive/ 4.2010/schukina.pdf

Shchmeleva, D. N. (1977). Russian language in its functional varieties (to the problem). Moscow.

Stepanov, Y. S. (1995). Language and science of the late 20th century. Alternative world, discourse, the fact and the principle of causality (pp. 34-72). Moscow.

Takhtarova, S. S. (2011). Strategy of argumentative persuasion. International Internet Conference "Argumentative rhetoric to practice political, business, and administrative and legal dialogue". Retrieved from http://iconf.vgi.volsu.ru/index

Van Dijk, T. (1978). Questions of pragmatics of the text (pp. 259-336). Moscow.

Vinogradov, V. V. (1954). Questions of Linguistics. The results of the discussion of style questions (pp. 60-87).

Vinogradov, V. V. (1980). On the language of fiction. Selected works. Moscow.

Voytak, M. (2003). Stereotyping and creativity in the text: Intercollege collection of scientific works. Religious style genologic perspective (pp. 323-329). Perm.

Weinrich, H. (1978). Text feature of the French article (pp. 370-387). Moscow.

Zavalnikov, V. P. (2003). The language of the holy image in ancient hagiography (Problems interdependence of linguistic and extralinguistic content language the image of man in a certain socio-cultural situation). Omsk.

Zhulynskaya, A. S. (2005). Genre space of religious texts (pp. 198-203). Scientific notes of TNU n.a. V. I. Vernadskiy. "Philology" series. V. 18 (57): Retrieved from http://workinggroup.org.ua/publzulinsk.shtml 